\title{
Responding to the Troubled Families Programme: Framing the Injuries of Inequality
}

\author{
Andrew Sayer \\ Department of Sociology, Lancaster University \\ E-mail: a.sayer@lancaster.ac.uk
}

Government initiatives such as the Troubled Families Programme present a difficult problem for social scientists: how to discuss the policies without accepting and appearing to legitimise the problematic framing of social problems that they embody. The programme is characteristically neoliberal in its silence on structural inequality and in its targeting of certain families as deficient and wholly responsible for their situation. Like so many such programmes, its primary addressee is arguably not merely those targeted by the policies but the wider electorate. The paper discusses the dilemmas of challenging the policy's framing. First it makes some general points about the different characters of political and academic discourses, before examining some key features of the framing of TFP, its conceptualisation of social causes of problems and individual responsibility, and how social scientists might respond. It then draws upon the work of George Lakoff to comment on how the impact of policy and political discourse depends on the kinds of value systems it invokes, before concluding.

Keywords: Framing, political discourse, social causes, responsibility, values.

\section{Introduction}

Government initiatives such as the Troubled Families Programme (TFP) present a difficult problem for social scientists: how to discuss such policies without accepting and appearing to legitimise the problematic framing of social problems that they embody and depend on. The programme is characteristically neoliberal in its silence on structural inequality and in its targeting of people as deficient and wholly responsible for their situation. Radicals are likely to want to repudiate the programme and to reject its blaming of individuals and families, but in so doing they expose themselves to accusations of denying facts of anti-social behaviour and of idealising the targeted groups. Further, given that there is not a simple deterministic relation between social disadvantage and antisocial behaviour, one cannot adequately explain the latter wholly in terms of the former. Yet poverty and inequality tend not to be ennobling. Rather than deny that any problematic behaviour can be due to injuries of class, we need to frame it in a way that acknowledges both the behaviour and the more complex causality that produces it. We also need to take account of the fact that any policy is also addressed to advancing its authors' wider political strategy.

In order to discuss how social researchers might respond to TFP, the paper first makes some general comments about political discourse, its character, its intended audiences, 
its relation to other discourses, and the significance of how issues are framed in social policy. Second, it looks at TFP in the light of these points and in relation to neoliberal politics, and assesses various critical responses to it from social science. Third, it draws on the work of George Lakoff on framing and value systems in political discourse, which suggests how to challenge neoliberal welfare policies such as TFP in ways that are likely to resonate with the public.

\section{Discourse, framing and audiences}

It would be naïve to assume that TFP was simply aimed at the particular families it identified, as if it were merely a neutral managerial response to problems whose definition was uncontroversial. Any social research that assumed this would be doomed to misunderstand its object, though it would make it easier for its authors to get a hearing from politicians. Social policies are not simply ways of dealing with alleged problems, but are always also - and sometimes more so - ways of advancing broader political strategies and worldviews, and gaining political support. Indeed, the electorate, reached via the news media, is arguably often the primary addressee.

The discourse of any particular policy or programme must therefore be understood not on its own but in its political context, both in terms of its origins and its intended audiences and effects. Such discourse overlaps with other kinds of discourses, including those of political speeches, broadsheet and tabloid newspapers, television news and the internet. As few members of the public read policy documents, their message is intended to be relayed through these other media, albeit it in their respective genres. ${ }^{1}$

Political discourse, especially regarding topics of popular concern, is predominantly eristic - that is, conducted in order to gain victory over opponents and persuade others by any means that works, regardless of whether the arguments are logical or illogical, empirically supported or not. It is driven by self-interest rather than a desire to find the best accounts, explanations, and courses of action, and it is characteristically impatient (Sayer, 2008). By contrast, in an ideal kind of discussion, or in an 'ideal speech situation', as Habermas termed it, the only motive would be that of finding the better argument, and participants would be willing to take time to consider others' ideas and change their minds if they proved superior (Habermas, 1979). Academic discourse aspires to this 'disinterested' form of argument, though of course it often falls short of the ideal. Hence, whereas academic discourse generally seeks to remove ambiguity, political discourse often exploits it, as is unusually clear in the very term 'troubled families'.

At the same time, we have to recognise that in everyday life, in contrast to (ideal) academic discourse, the persuasiveness of particular political discourses depends heavily on how they play into implicit but powerful systems of value and emotion (Lakoff, 2004). Thus, social policies may sometimes be best understood as being partly intended to change or reinforce these wider feelings and prejudices as well as to address their target issue. I shall argue that this is the case for the TFP.

Finally, in assessing any social policy, it is always important to question the way in which it frames its topics: What is taken as given that might be questioned? What things are treated as parameters rather than variables? How does the definition and bounding of the problem limit diagnoses and prognoses?

Much 'policy science' takes the goals and framing of policies as given and merely assesses ways of achieving those goals that are allowed within that framing. Different 
framings not only suggest different accounts and explanations, but different ways of assigning responsibility for problems and hence different allocations of blame or credit. They lead not merely to technical judgements about causes and what should be done but moral judgements of the behaviour of individuals and institutions.

We can now look at the TFP with these points in mind.

\section{The framing of the Troubled Families Programme}

Recent policies such as TFP reflect the evolution of neoliberalism over the last four decades. Attacks on the welfare state, begun under the Thatcher and Major administrations and continued by New Labour, accused it of allowing its beneficiaries to avoid taking responsibility for their own actions and the consequences of these actions. Since the 2008 crash, the alleged necessity of austerity has been used to justify further welfare cuts.

One of the key characteristics of neoliberal political discourse is its selective refusal of social, and especially economic, explanations of social problems. Thatcher's hardline denial of the notion of society was later softened by communitarian influences under Blair and Cameron's notion of 'the Big Society', but the evasion or denial of the effects of economic processes on life chances and behaviour has remained a constant. Individuals are thus held largely or wholly responsible for their fortunes. If their pasts have been difficult, they can and must take steps to free themselves from their pasts from now on. This individualistic understanding of society fits well with commonsense thought. There are never job shortages, just under-motivated jobseekers who need to try harder to get work. There are never structural problems of poorly paid jobs, just individual workers who could be paid more if only they gained skills and worked harder. The fallacy of composition - that what is possible at certain times for some individuals must also be possible for all simultaneously - is a staple of neoliberal political discourse; zero-sum games cannot be acknowledged. Individuals are thus 'responsibilised' for dealing with problems that may originate elsewhere and which formerly might have been addressed by the welfare state (Shamir, 2008).

This framing fits with the idea of a meritocratic society and what psychologist Melvin Lerner called the belief in a 'just world' - a world in which people largely get what they deserve, so that effort and merit are rewarded and their opposites penalised: people are paid what they are worth, and worth what they are paid (Lerner, 1981). In political discourse, it is often unclear whether concepts like meritocracy are meant to describe current society, predict a new world that lies ahead or prescribe one. Such ambiguity is useful.

Although many social scientists emphasise structural causes of social problems, there is also a long history of social researchers lending support to what might be termed antipoor policies, for example through notions of a 'culture of poverty', 'welfare dependency' or an 'underclass' (Murray, 1994; Welshman, 2006). Under neoliberalism, the influence of these latter researchers has grown, while those social scientific explanations which give considerable weight to social causes of individual characteristics and behaviour are viewed with suspicion both by neoliberals and the public as excusing individuals of any responsibility for their actions. But then, as we shall see, reconciling individual responsibility and social influences is no easy matter, and sociology in particular has often left little or no room for individual reflexivity and responsibility. 
Over the last twenty years we have seen a gradual shift in social policy discourse from explanations for social problems that refer to history, backgrounds and social contexts, to ones which discount these, replacing understanding with moral judgement of individuals and correction of their behaviour. As former Prime Minister John Major once suggested, we should 'condemn a little more and understand a little less' (interview with the Mail on Sunday, 21 February 1993). This of course is emblematic of a shift in worldviews from Left to Right.

The 'responsibilisation' strategy was clear in New Labour policy, though there are many historical precedents (Welshman, 2006). It involves a shift away from a rights-based view of welfare benefits to a more disciplinary, contractual view in which benefits are conditional on evidence of 'responsible' conduct, particularly being employed - hence 'workfare', and a corresponding shift of focus from needs to behaviour. TFP itself has its precedents in family policies pioneered by New Labour. In linking social policy to criminal and anti-social behaviour, it represents a criminalisation of social policy (Burney, 2005; Rodger, 2008). This was a risky strategy insofar as many Labour voters still regarded structural features as significant causes of social problems, and supported the notion of a welfare state that offsets these and provides a safety net. This is presumably why, even though New Labour's social policies increasingly attempted to discipline individuals, this was described in policy documents as 'support'.

In 1997, this Government inherited a welfare state weighted heavily towards rewarding and supporting people who were not actively seeking to improve their situation, whether by looking for work or by taking part in training ... Too many people lacked both the aspirations and the support to get back to work. (Gordon Brown, in DWP, 2008: 5)

Like Brown, only in stronger language, Cameron attributes an alleged decline in responsibility to the welfare state.

For years we've had a system that encourages the worst in people - that incites laziness, that excuses bad behaviour, that erodes self-discipline, that discourages hard work ... above all that drains responsibility away from the people. (Cameron, 2011)

But then the families are held responsible for a variety of social problems:

For years we've known that a relatively small number of troubled families are responsible for a large proportion of the problems in our society. Maybe the parents have an addiction or have never worked in their life. Maybe there's domestic violence. Often the children are completely out of control. (Cameron, 2010)

In the TFP, the shift from social explanations to moral condemnation is matched by a heavier emphasis on discipline and punishment:

families signing up to a contract that offered a mix of support and challenge to them [sic] with a new threat of sanction if families refused help. (DCLG, 2012: 11)

the threat of sanctions such as loss of tenancy 'concentrates the mind' of families and is a key mechanism for bringing about change. (DCLG, 2012: 28) 
On the face of it, the term 'troubled families' suggests they are beset by external problems, and are troubled in the sense of being anxious about or disturbed by certain things. While this could be construed as compassionate, it is clear from the above that it is nothing of the sort (Levitas, 2012a). Presumably, the government did not want to risk using a more inflammatory word like 'troublesome' in official documents, and it could signal its intention in more informal and direct terms elsewhere, while relying on the tabloid press to elaborate the narrative and provide graphic illustrations of 'benefit cheats' and the like for popular consumption. Further resonance was provided by a string of television programmes such as 'Benefits Street', 'We pay your benefits'; 'On benefits and proud' (Jensen, 2014; Tyler, 2014) that invited audiences to condemn and despise its subjects. Yet, it has to be acknowledged that such programmes - political and televisual - were popular, including among many who themselves benefitted from the support of the welfare state (Shildrick and MacDonald, 2013). The cheats, scroungers and skivers, were always other people, less deserving and supported by the long-suffering deserving majority.

Explanations in terms of external circumstances such as local economic decline and lack of adequate jobs were conspicuously absent. A report published by Louise Casey, Director General of the TFP, called Listening to Troubled Families, contained not one mention of poverty. The title turned out to be another misnomer, in that the narratives of the selected families themselves were discounted, and peremptorily glossed with Casey's own explanations:

it was clear that the reasons for that behaviour had come from the household itself - the poor parenting skills, the constant changes in the home, family and partners, and the ongoing verbal and physical violence. (Casey, 2012: 59, cited in Bond-Taylor, 2015)

As MacLehose comments, the families were defined by their behaviour, not by their experiences and situations (2014: 42-3).

Yet while the misuse of evidence appealed to in TFP policy discourse to suit the political climate and strategy has been pointed out by experts on social policy (Levitas, 2012a; MacLehose, 2014), it does not follow from this that none of the pathologies that it claims to identify exists. One can analyse how the allegedly troubled families have been 'constructed' by the government and policy makers, but some of the anti-social behaviours - theft, physical and verbal abuse, child neglect - are real and serious; they cannot all be dismissed as tabloid inventions. Consequently, opposing the stigmatisation and symbolic violence of the policy and media discourses by denying any culpability at the level of the individuals is problematic, and offensive to those who are victims of anti-social behaviour. Note too, that the denial of responsibility is typically selective: sociologists do not generally deny or ignore individual responsibility in cases of racism, rape or murder, nor do they treat them as products of (mis)labelling or negative social construction by the dominant. Further, while it is indeed important to stress social causes, analyses that leave no space for any individual responsibility, whether causal or moral, are problematic because they render people as helpless victims, having no agency.

On the other hand, accounts of behavioural problems that allow a qualified role for individual responsibility are at risk of being claimed by the Right as support for their own unqualified, one-sidedly individualistic views, and painted by the Left as conceding the blaming and stigmatisation of the dominant discourse. Even to appear to step partly 
within the dominant frame is to risk being captured by it, or at least of being accused of it, though the risk may be lower in patient academic discourse than within more eristic, impatient debates. So strategically, within eristic debates, it may often be best simply 'not to go there', and talk instead about social causes of problems. This has been common amongst social researchers, and indeed generally I would recommend it on such occasions. But sooner or later one is likely to have to confront the individualistic accounts and acknowledge that some behaviour is seriously anti-social. It could take decades to change the broader social causes, and even then, given that dispositions acquired from early life are hard to change, one might not expect problematic behaviours to disappear quickly.

A strategy of denying problematic behaviours underestimates the extent of injuries of class and other forms of inequality and confuses partisanship with critique. The case against it has been well made by Martha Nussbaum through the example of Joseph Steinbeck's famous book, The Grapes of Wrath. In that story, the impoverished migrants face a succession of disasters, injustices and indignities, and yet retain their dignity and generosity. Their moral qualities are undiminished, even strengthened by their experience, so the story easily wins our sympathy and co-opts our sense of injustice. But it is also a romantic conceit:

Steinbeck gives the rich an easy time, really: for he shows that all injustice can produce is unhappiness. If we understand that injustice can strike its roots into the personality itself, producing rage and resentment and the roots of bad character, we have even deeper incentives to commit ourselves to giving each child the material and social support that human dignity requires. (Nussbaum, 2001: 414)

Inequalities tend to injure people - that is mainly why they are so problematic (Sennett and Cobb, 1972; Sennett, 1998; Sayer, 2005). Poverty, insecurity, exclusion, stigmatisation and a depressed/ing environment make daily life extremely difficult and are not ennobling. Those difficulties do not necessarily lead to the pathologies highlighted in the TFP discourse: the relation is probabilistic rather than deterministic. And as Shildrick et al.'s empirical studies of families living in poor areas shows, they are not found in most such families (Shildrick et al., 2012). ${ }^{2}$ Nevertheless, poverty and inequality can harm people in many ways, including causing stress and ill-health, making conflict more likely and reducing faith in legitimate ways of making a living (Charlesworth, 2000; Wacquant, 1999). In turn, anxiety and susceptibility to depression can reduce the ability to make rational decisions. Further, psychological research on altruistic behaviour shows how it is encouraged (discouraged) by good (bad) treatment and conditions that people experience (Appiah, 2008). Research on attachment in early life shows that neglect and abuse of children can make it hard for them to cope well in later life, and can cause behavioural problems that are difficult to change (Cassidy and Shriver, 1999). Note again the qualifiers - 'are likely to', 'can': there are often over-riding factors that inhibit these pathologies, such as strong support networks of family and friends. There may also be strengths fostered by living with poverty and exclusion, such as resilience, toughness and experience of dealing with heavy responsibilities.

A common response from the Right to claims that behavioural problems are substantially caused by poverty and inequality is that these do not justify anti-social behaviour and criminality. Hence, in eristic discourse, those who point to such conditions 
can easily be put on the defensive: 'are you saying poverty justifies violence?'. The challenge confuses explanations of behaviour with justifications. Much behaviour lacks moral justification, but is nevertheless made more or less likely by particular circumstances. An under-regulated financial system does not justify irresponsible actions that risk crashing the economy, but causally it makes them likely.

The intergenerational transmission of advantages and disadvantages is a further difficult issue to address in debates on social policy. The Right either ignores it as an inconvenient fact for narratives of social mobility and meritocracy, or selectively exaggerates it through references to a culture of poverty or alleged genetic inferiority or, more specifically, through claims that there are families that have not worked for three generations. Empirical research shows the latter not to be true, and that the typical pattern for the most disadvantaged families is to move in and out of work (Shildrick et al., 2012). In an eristic context, it can be difficult both to acknowledge that children are likely to take on the disadvantages of their parental context, and to counter politically motivated attempts to blame their parents' approach to child-rearing. As Welshman shows, the history of social policy is littered with cases of folk beliefs about the poor that keep returning usually in new guises - no matter how many times social research shows them not to be true (Welshman, 2006).

While TFP is clearly an example of 'responsibilisation', this concept also needs qualification. As is typical in the Foucauldian tradition, it is 'crypto-normative' (Sayer, 2011); that is, the description sounds ominous and suggests something problematic, yet fails to explain why. Are all forms of responsibilisation problematic or only certain forms? After all, in their daily lives, Foucauldians, as much as anyone else, hold people responsible for certain actions. Responsibilisation is problematic where it expects individuals to resolve problems for which they cannot reasonably be held responsible, or correct effects of formative influences which are difficult to change. But it is not easy to distinguish what people can and cannot be expected to do, given their backgrounds and current situations, including existing opportunities and constraints. Just what in each case is reasonable to expect and what is too much is partly a practical question of what is feasible given constraints and available resources, and partly a normative matter of what people should be willing to do and what lengths they should go to in overcoming constraints and limitations. ${ }^{3}$ Punitive observers, such as Casey, attach little importance to such constraints. What can be said is that, other things equal, the greater the incidence of poverty, neglect, inequality, marginalisation and stigma, the less we should be surprised that behavioural problems will arise. However we might choose to judge the behaviours, their incidence is heavily influenced by social circumstances, and available 'cultural toolkits' for dealing with them (Swidler, 1986), so for practical as well as academic purposes, we need to understand more and condemn less. Neoliberal discourse systematically ignores these structural forces, but given the massive impact these have on individuals and families, any adequate response to policies like TFP must, above all, highlight them rather than remain with the narrow frame set by the official discourse or indeed that of the academic discipline of social policy.

\section{Value systems and framing in political discourse}

It is easy for academics, accustomed to prioritising reasoned analysis, to underestimate the extent to which the effectiveness of political discourse depends not on the adequacy 
of its arguments and evidence, but on how it plays into major systems of values. To varying degrees, its authors know this. George Lakoff, the US cognitive linguist, argues that elections are decided primarily on values rather than policies, and that if progressives are to win against the Right, they need to realise this and stop arguing about policies within value frames set by their opponents, and argue instead from and for their own values (Lakoff, 2004). The Right, by contrast, seem to be aware that communicating general values favourable to their policies is more effective than explaining the policies themselves.

Lakoff (2004) argues that the Republicans mobilise a frame of values involving a 'strict father model'. This involves obedience to authority, self-discipline and self-reliance, patriarchal families and heteronormativity, respect for the wealthy as deserving and contempt for the dependent as undeserving, as in the just world ideal. Outsiders - anyone who is different - are regarded with suspicion and fear: conformity connotes morality. Empathy and compassion are associated with gullibility and weakness. In this model, conviction trumps reason: intellect is seen as redundant and dangerous, and those who need to appeal to evidence, arguments and experts are regarded as weak, 'flip-flop' people who do not know what they think. ${ }^{4}$ Explanations are already to hand, commonsense is authoritative and what is needed is firm action; the strong father always already knows what is right and will protect all those who put their trust in him. The more populist political discourse on TFP exemplifies this value framing. Insofar as official documents refer to empirical evidence, they do so in ways that support the policy and its value frame.

Lakoff (2004) recommended that in political debate, rather than respond within this frame, 'progressives' (American left liberals) should use their own, 'nurturant parent model' as an alternative; he claimed this would appeal to voters if characterised effectively. It has a more compassionate and generous view of others, is open to difference, values dignity and respect for all, and values reason and evidence over simple authority per se. Lakoff argues the two value frames involve different neural systems, and that while most people may operate with a mix of each, the balance can be influenced by discourse and actions which reinforce one rather than the other.

$\mathrm{He}$ also argues that conservatives tend to think in terms of simple, direct causation; if a child is neglected or abused by an alcoholic parent, then we need look no further for an explanation of this outcome and can proceed immediately to the solution: discipline to change behaviour. Progressives, by contrast, appeal to more inclusive, complex, systemic explanations, similar to those of sociology, which imply a wide range of measures to resolve the problem. While this means that in eristic discourse they have a more difficult task in having to make complex, qualified arguments persuasive, Lakoff (2004) argues that by mobilising vocabularies that chime with the nurturant parent system of values, there are ways of succeeding in such contexts.

\section{Conclusion}

I have argued that with greater awareness of the kinds of discourse and framings used in discussions of social policy, social scientists may be able to give more penetrating and effective evaluations of social policies and their reception, and possibly - bearing Lakoff's points in mind - achieve more impact and resonance among the wider public.

While being wary of the twin evils of stigmatising and idealising the poor, social scientists need to recognise that poverty is not ennobling; it can damage people and 
produce common pathologies. They are a key reason why poverty is so bad. The difficulty for social scientists is how to acknowledge that anti-social and self-destructive behaviour does happen, while highlighting the structural features of society that produce poverty, inequality and insecurity. Although the symbolic violence directed against disadvantaged people in the TFP discourse must be challenged, it is not enough to oppose the programme merely in terms of stigmatisation and misrecognition, for these are more misguided responses to disadvantages caused mainly by economic deprivation than primary causes of those disadvantages. Even without the blaming and responsibilisation of TFP and other 'workfare' policies, those targeted by the programme would be disadvantaged. Part of the problem of social policy research and commentary is precisely that it tends to be limited to policies themselves and to allow deeper causes of social problems to remain hidden: other social scientists - political economists, for example, deal with many of these. In this paper, I have tried to indicate how social researchers responding to programmes like TFP need to find ways of acknowledging and communicating the complex causality behind the problems the policies address, while remaining vigilant about the risks of involvement in eristic debates about politically sensitive issues and adopting appropriate strategies for navigating them.

\section{Acknowledgement}

Thanks to Betsy Olson for discussions of some of these issues.

\section{Notes}

1 In critical discourse analysis this is known as a 'genre chain' (Fairclough, 2003).

2 Notwithstanding the TFP's misuse of data on multiple deprivation as a measure of anti-social behaviour (Levitas, 2012a and b), deprivation makes the latter more likely to occur.

3 In political philosophy, particularly following Rawls' Theory of Justice, it has become common to see motivation itself as significantly affected by social circumstances and types of upbringing, so that individuals are not held substantially responsible for motivation (Rawls, 1971).

4 John Kerry was called this by Republicans for his habit of defending policies in this way (Lakoff, 2004).

\section{References}

Appiah, K. A. (2008) Experiments in Ethics, Cambridge, MA: Harvard University Press.

Bond-Taylor, S. (2015) 'Tracing an ethic of care in the policy and practice of the Troubled Families Programme', Getting with the Programme, Social Policy Association Troubled Families Workshop, 11 February, https://www.dur.ac.uk/resources/sass/SBond-Taylor-TracinganEthicofCare.pdf [accessed 10.06.16].

Burney, E. (2005) Making People Behave: Anti-social Behaviour, Politics and Policy, London: Routledge. Cameron, D. (2010) 'Speech on families and relationships', 10 December, https://www.gov.uk/ government/speeches/speech-on-families-and-relationships [accessed 10.06.16].

Cameron, D. (2011) 'PM's speech on the fightback after the riots', 15 August, https://www.gov.uk/ government/speeches/pms-speech-on-the-fightback-after-the-riots [accessed 10.06.16].

Cassidy, J. and Shriver, P. R. (eds.) (1999) Handbook of Attachment, New York, NY: Guilford Press.

Charlesworth, S. (2000) A Phenomenology of Working Class Life, Cambridge: Cambridge University Press. Department for Communities and Local Government (2012) Working with Troubled Families: A Guide to the Evidence and Good Practice, December 2012, London: DCLG. 
Department of Work and Pensions (DWP) (2008) 'No one written off: reforming welfare to reward responsibility', Public Consultation Paper, July, https://www.gov.uk/government/uploads/system/ uploads/attachment_data/file/238741/7363.pdf [accessed 10.06.16].

Fairclough, N. (2003) Analyzing Discourse: Textual Analysis for Social Research, London: Routledge.

Habermas, J. (1979) Communication and the Evolution of Society, London: Heinemann.

Jensen, T. (2014) 'Welfare commonsense, poverty porn and doxosophy', Sociological Research Online, 19, 3, 3, http://www.socresonline.org.uk/19/3/3.html, DOI: 10.5153/sro.3441 [accessed 10.06.16].

Lakoff, G. (2004) Don't Think of an Elephant! Know Your Values and Frame the Debate, White River Junction, VT: Chelsea Green Publishing.

Lerner, M. J. (1981) The Belief in a Just World: A Fundamental Delusion, New York: Plenum.

Levitas, R. (2012a) 'There may be "trouble" ahead: what we know about those 120,000 troubled families', Poverty and Social Exclusion, http://www.poverty.ac.uk/policy-response-working-papers-familiessocial-policy-life-chances-children-parenting-uk-government [accessed 10.06.2016].

Levitas, R. (2012b) 'The government has misrepresented research findings on "troubled families", blaming the poor, not coalition policies, for rising poverty levels', LSE Politics and Policy Blog, 14 June, http://blogs.Ise.ac.uk/politicsandpolicy/troubled-families-misrepresentation-levitas/ [accessed 10.06.2016].

MacLehose, A. (2014) 'A Foucauldian analysis of 'Troubled Families', unpublished Ph.D. thesis, University of East London, http://roar.uel.ac.uk/3964/1/u1037633\%20thesis\%20docx\%20.pdf [accessed 10.06.16].

Murray, C. (1994) The Underclass: the Crisis Deepens, London: Institute of Economic Affairs.

Nussbaum, M. C. (2001) Upheavals of Thought, Cambridge: Cambridge University Press

Rawls, J. (1971) A Theory of Justice, Oxford: Oxford University Press.

Rodger, J. J. (2008) Criminalising Social Policy: Anti-social Behaviour and Welfare in a De-civilised Society, Cullompton: Willan.

Sayer, A. (2005) The Moral Significance of Class, Cambridge: Cambridge University Press.

Sayer, A. (2008) 'Values and strategies of argumentation in everyday life, politics and social science', Academia.edu, April, https://www.academia.edu/13993096/Values_and_Strategies_of_ Argumentatin_in_Everyday_Life_Politics_and_Social_Science [accessed 24.04.08].

Sayer, A. (2011) Why Things Matter to People: Social Science, Values and Ethical Life, Cambridge: Cambridge University Press.

Sennett, R. (1998) The Corrosion of Character: The Personal Consequences of Work in the New Capitalism, London: W. W. Norton.

Sennett, R. and Cobb, J. (1972) The Hidden Injuries of Class, New York: Alfred A. Knopf.

Shamir, R. (2008) 'The age of responsibilization: on market-embedded morality', Economy and Society, $37,1,1-19$.

Shildrick, T., Macdonald, R., Furlong, A., Roden, J. and Crow, R. (2012) 'Are 'cultures of worklessness' passed down the generations?' Joseph Rowntree Foundation Report, http://wbg.org. uk/pdfs/worklessness-families-employment-full.pdf [accessed 10.06.16].

Shildrick, T. and MacDonald, R. (2013) 'Poverty talk: how people experiencing poverty deny their poverty and why they blame "the poor"', Sociological Review, 61, 2, 285-303.

Swidler, A. (1986) 'Culture in action: symbols and strategies', American Sociological Review, 51, 2, $273-$ 86.

Tyler, I. (2014) 'Being poor is not entertainment: class struggles against poverty porn', Social Action and Research Foundation, 16 November, http://www.the-sarf.org.uk/being-poor-is-notentertainment-class-struggles-against-poverty-porn-by-imogen-tyler/ [accessed 10.06.16].

Wacquant, L. (1999) 'America as dystopia', in P. Bourdieu et al., The Weight of the World: Social Suffering in Contemporary Society, Cambridge: Polity.

Welshman, J. (2006) Underclass: A History of the Excluded, London: Hambledon Continuum. 